\title{
Lived experiences of homelessness among elderly women: a phenomenological study
}

\author{
EBTESAM MO'AWAD EL-SAYED EBIED ${ }^{1}$, NAGLAA EL-SAYED ELDARDERY² \\ ${ }^{1}$ Assistant professor of gerontological Nursing, Faculty of Nursing, Cairo University, Egypt. \\ ${ }^{2}$ Assistant lecturer of gerontological Nursing, Faculty of Nursing, Cairo University, Egypt.
}

\begin{abstract}
Background: Homelessness is a global issue that has a devastating impact on elderly women's health. It is estimated that 100 million people are considered homeless worldwide.

Aim: to explore the lived experiences of homelessness among elderly women.

Research question: What are the lived experiences of homelessness among elderly women?

Sample: A purposive sample of 30 homless elderly women.

Setting: a selected homelessness shelter.

Tools: 1- A structured questionnaire of personal and medical data. 2- Semi-structured interview with open-ended questions. 3- Field notes.

Results/Themes: five themes were represented; (1) Living without basic human needs (food, water, sleep \&shelter), (2) Self-care deficit. (self-neglect, poor hygiene and bad odor). (3) Bio- psycho- social health problems (fear, aggressive behavior, depression, suicidal ideation, isolation, hopelessness, loss of family role, vision problems, diabetic foot and lack of acces to health care services), (4) Emotional distress (uncertainity, loss of interest, suicidal ideation, bad feeling, feeling lonely), (5) Strategies for resolution (religious and expression of feelings).

Conclusion: Majority of homless elderly women experienced living without basic human needs, bio-psychsocial health problems, self-care deficit which predispose them to many devastating health consequences.

Recommmendations: Employ urgent interventions to solve the unique and challenging health problems/needs of this vulnerable group; raising community awarness about the nature, and process of homelessness phenomena and conduct bio-psychosocial interventions studies of homeless elderly women.
\end{abstract}

Key words: Lived experiences, homeless elderly women, phenomenological study.

\section{INTRODUCTION}

The Canadian Homelessness Research Network (2012) defined homelessness as "the situation of an individual or family without stable, permanent, appropriate housing, or the immediate prospect, means and ability or acquiring it". Four living circumstances fall under the umbrella of homelessness;1) Unsheltered, or absolutely homeless and living on the streets or in places not intended for human habitation;2) Emergency sheltered, including those staying in overnight shelters for people who are homeless, as well as shelters for those impacted by family violence; 3) Provisionally accommodated, referring to those whose accommodation is temporary or lack security of tenure, and finally,4) At risk of homelessness, referring to people who are not homeless, but whose current economic and/or housing situation is precarious or does not meet public health and safety standards (Ahadmin, 2014). Aging is a global phenomenon and the group of age 60 years or older is growing fast. According to data from World Population Prospects: the 2017 Revision, the number of elderly is expected to be more than double by 2050 and to be more than triple by 2100, rising from 962 million globally in 2017 to 2.1 billion in 2050 and 3.1 billion in 2100 . As such, one of the main features of the Egyptian population over the last few decades is the gradual increase in the absolute and relative numbers of older people (United Nations, 2017).

It is worth saying that, these profound demographic changes will inevitably place heavy burdens on families who are assumed the responsibility in providing care for elderly (Boggatz, Farid, Mohammedin, \& Dassen, 2016). Notably, broken social networks such as dysfunctional families, lack of family support or family problems is a substantial factor that contributes to homelessness (Mabhala, Yohannes, \& Griffith, 2017). Other risk factors for homelessness includes chronic mental illness, addiction, family disruptions, and sudden or protracte unemployment (Fotheringham, Walsh, \& Burrowes, 2013).

Additionally, homelessness has a direct adverse biopsychosocial impact on elderly health. Homeless elderly are susceptible to the development of prevalent physical conditions that impair their quality of life such as cardiovascular diseases, diabetes, exposure to tuberculosis or infestations (scabies and lice), long periods of walking, standing due to the prolonged exposure to moisture and cold, cellulitis venous stasis and fungal infections (Liu \& Estrada-Hernández, 2010), (Oliveira, Pereira, Azevedo, Lunet. 2012), ( Fazel, Geddes, Kushel. 2014) \& (Brown et al., 2016).

In addition to medical implications, older adults experiencing homelessness encounter psychological impairments such as personality disorders, depression, psychosis, and low quality of life (Gilmer, Stefanic, Ettner, Mannig \&Tsemberis. 2010) \& (Sullivan, Burnam, Koegel, Hollenberg, 2000), functional disabilities (van der Plas, Hoek, van Hoeken, Valencia, van Hemert, 2012), \& suicidal behaviors (Cheun, Hwang. 2004) \& Filtzpatrick, Lagory, Ritchey. 2007 (Johnstone, Jetten, Dingle, Parsell, \& Walter, 2015).

It is also estimated that the prevalence of depression among all subpopulations of individuals experiencing homelessness is between 40 and $80 \%$, which is twice the rate among populations not experiencing homelessness (McDonald, Donahue, Janes, \& Cleghorn, 2006). 
Furthermore, certain health conditions (particularly mental illness) may contribute to the onset of homelessness problem and then in turn be exacerbated by the homeless state. As the number of older adults experiencing homelessness continues to increase so, understanding the homelessness phenomenon among elderly women is necessary in order to positively deal with the issue (Seattle \& County, 2015) \&(Bulter, 2017).

Significance of the study: Homelessness is a complicated and multifaceted national and international health problem affecting all ages. It is difficult to gather general estimates of the homeless population because homeless elderly live in transition and often lack a fixed address. According to reports issued by the Ministry of Social Solidarity, there are at least 12 million homeless in Egypt, and the problem is most severe in Cairo, Giza, Qalioubiya, and Alexandria (Manal, \& Magda, 2018). There is a also gap of knowledge about homelessness problem among elderly in Egypt (Leila, 2019). Understanding the experiences of homelessness among elderly women and the unique challenging health needs of this vulnerable population could help in empowerment of homeless elderly women and prevention of homelessness problem by raising community awareness about the problem. Knowledge and related results gained from this study will also help in identifying personal, environmental, and medical risk factors contributing to homelessness problem among elderly and could also laid the groundwork for further future researches about this significant health problem.

Notably, the experiences homelessness have been narrowly discussed despite their overrepresentation among elderly. The paucity of research specifically focusing on older homeless elderly does little to answer the question regarding the causes and challenges of homelessness among elderly women in Egypt. More information and understanding is necessary to design interventions that meet homeless elderly health needs/problems. Much of the research related to older adults' homelessness is quantitative or conceptual in nature (Brown et al., 2013; Gonyea et al., 2011). Thus, a major purpose for this study was to explore, understand, identify and illuminate the lived experiences of homeless elderly. Current study will also explore the challenges homeless elderly women face from the eyes of the homeless elderly women such as biopsychosocial health problems, financial burdens, being in the street without home, poor self-care, lack family support.

Qualitative phenonmenological approach help the nurse to examine the phenomena of homelessness in many different sections rather than examine its quantitative subject and allow homeless elderly to express theses life experiences more freely and allow the nurse to discover more hidden themes. Additionally, carrying out this research will hopfuly identify factors that pose threats for the homeless elderly population. Findings of the current study could be used to change public policy to promote action by coalitions of public and private agencies to eliminate homelessness among elderly women.

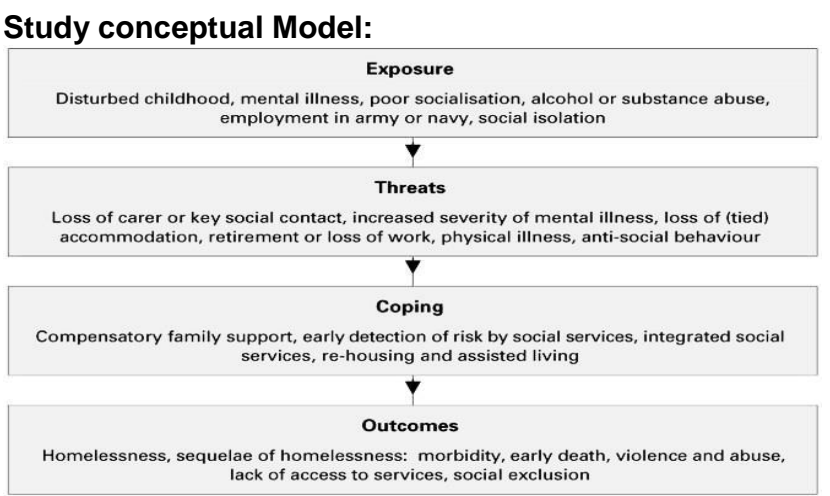

Figure (1) Vulnerability to homelessness in old age conceptual model (Schröder-Butterfill \& Marianti, 2006)

Vulnerability to homelessness in old age conceptual model is composed of 4 vulnerability components; exposure, threat, coping capacity and negative outcomes:

1- Exposure is susceptibility or risk factor for being homeless, mental illness and poor socialization increase the risk of abuse at the hands of careers, institutionalization, or homelessness.

2- Threats are specific events that lead to negative outcomes of being homeless such as declines in health and physical strength, disability, loss of income, loss of a spouse or other network members, particularly affect older people in that they arise from the biological and social processes of ageing.

3- Coping capacities Coping capacities are the set of assets and relationships that allow people to protect themselves from a 'negative end' or to recover from a crisis, coping capacities fall into three broad groups; individual capacities (personal wealth education, skills and health, elderly personal adaptations), 2- social networks (family, friends, neighbors), and formal social protection (community institutions like religious and voluntary associations, mutual assistance arrangements and charity) that reduce older people's vulnerability by providing support, companionship or advocacy.

4- $\quad$ Outcomes of vulnerability may be negative, such as lower health, poor personal care and malnutrition, difficulty managing basic medications and personal finances, living in unsafe environments, medical morbidity and death. Vulnerability outcome may be positive such as social competence and gradual return to normal levels of functioning) with effective intervention.

\section{SUBJECT AND METHODS}

Aim of the Study: to explore the lived experiences of homelessness among elderly women.

Research question: What are the lived experiences of homelessness among elderly

women?

Research Design: A qualitative phenomenological approach was chosen to focus on homelessness experiences among elderly women, to explore the challenges that homeless elderly face, such as lack of basic human needs, lack of social support, cultural issues, health problems, financial burdens and poor quality of life 
as experienced by homeless elderly. Researchers "centers on the attempt to achieve a sense of the meaning that others give to their own situations" (Peters \& Halcomb, 2015).

Setting: The study was conducted in a selected shelter for homelessness at Cairo governorate "Together to Save a Human". It is the only Egyptian foundation that provide safe residence, food, medical, social health services for both men and women homeless elderly. The shelter is composed of two departements; one for men and the other one for women. Current study was conducted in women's departement located at Elharm city. It is composed of three floors each floor contain four shared rooms and a hall.

Sample: Purposive sample of 30 homeless elderly women. Inclusion criteria: aged 60 years and older, newly admitted to the shelter within one month, lived in the street for more than 1 year, able to communicate and free from any mental health problems, lived the experience of homelessness phenomenon under study and being interested in participating in the study.

Data Collection: collection, coding, and analysis of data are blended throughout the study. Data consisted of interview transcripts and field notes from observations are treated to rigorous ongoing analysis. Study tools: 1Structured questionnaire to collect elderly personal and medical data. 2-An interview schedule to fill in a semistructured questionnaire including open-ended questions about elderly lived experiences during homelessness period in the street. The interview guide consisted of series of 5 open ended questions designed by researchers to encourage the flexibility of responses and to let elderly express themselves freely in their own words and allow a deeper exploration, description and understanding of their experiences. Participants were also given the opportunity to discuss issues beyond the questions.

The interview guide consisted of series of 5 open ended questions designed by researchers:

1- What are your experiences during homelessness period in the street?

2- What are the difficulties you faced during homelessness period while you were in the street?

3- How did you adapt to difficulties during homelessness period in the street?

4- What were the major influences that contributed to your homelessness?

5- How do you keep going; what gives you meaning?

Ethical consideration: After approval of research ethics committee from Faculty of Nursing, Cairo Un iversity, the aim, purpose, and nature of the study were clearly explained to each participant.Privacy and confidentiality; Interviews were scheduled at a time and place convenient for the participants. Privacy during interviews was maintained by using private place in the shelter. Confidentiality was maintained by keeping the information obtained during the interview accessible to only researchers and only aggregate data being presented in the study. Summary, transcripts were stored in passwordprotected files on the laptop. All documents were kept in the researchers university office and locked in a file cabinet. Data will be stored for 3 years before discard. participants were reminded about the member checking phase of the study. If participants were interested in the member checking phase, they were asked to schedule a follow-up interview to discuss their transcriptions and emergent themes.Written consent was obtained by researchers from each participant. Participants were informed that participation was completely voluntary and they could refuse to participate or withdraw at any time. The interviewees known that the interview would be transcript and they agree. Researchers were honest, fair, and respectful toward participants and not attempted to mislead or deceive participants. Confidentiality, dignity, and rights as well as individual differences were respected. Trustworthiness was established through credibility, dependability, confirmability, and transferability using the guidelines developed by Lincoln and Guba (Lincoln \& Guba, 1985; Polit \& Beck, 2017).Credibility gained through triangulation by asking the same research questions and collects data from different sources. Member checks occur when researchers asks elderly women to review the data collected by interviewers and the researchers' interpretations of that data, Each interviewer wrote notes on the interview process to ensure that each aspect was appropriate according to the interview guidelines and conducted a briefing before each data collected. Transferability included purposefully sampling according to the study criteria and objectives to obtain a range of experiences, and by providing a description of the context of nurses' experiences. Confirmability was ensured by evaluating the research process during meetings and the reading and analysis of the data together as a team), Dependability was ensured by defining clear study stages, keeping research diaries, having regular weekly coordination, and ensuring accurate data coding., and confirmability.

Data collection procedure: Once a permission was obtained from administrator of shelter, elderly women were informed about the purpose and nature of the study. First, researchers established rapport with the elderly women to obtain their cooperation before any attempt to collect data. Written informed consents were obtained from every participant who accepted to participate in the study. Then, an interview schedule was created for participants who consented to the study. After accessing the participants and spending an appropriate time with them, each participant personal characteristics have been digitally recorded and transcribed verbatim. Interviews lasted between 30- 45 minutes. Data was collected by researchers individually (face to face) in a private place using the guiding interview questions twice weekely until coplection of data collection and saturation. Interviews were recorded by handwriting and transcribed. According to the results of the questionnaire, follow-up interview was scheduled to discuss their transcriptions and emergent themes.

\section{RESULTS / DATA ANALYSIS}

The recorded interview data were transcribed and subsequently combined with notes taken during the interview then studied thoroughly to analyze their meaning by researchers. Transcribed interviews and researcherss' notes were analyzed, validity of the findings was improved through member checks and researchers' bracketing to control bias. Analysis was done manually after reading the 
transcript again and again. And with each re- reading, new insights obtained to be possible to make associations and connections between different aspects of the data and significant statements about homeless were identified. Researchers discussed and identified similarities and differences and this was then grouped into themes Then themes were collected and identified in a table clarifying it regarding participants' words. The following (7) steps of Colaizzi's method were utilized to guide data analysis:

(1) Read all participants' descriptions of the phenomenon,

(2) Extract significant statements that pertain directly to the phenomenon,

(3) Formulate meaning for these significant statements,

(4) Categorize the formalized meaning into clusters of themes,

(5) Integrate the findings into an exhaustive description of the phenomenon,

(6) Validate the exhaustive description by returning to some of the participants to ask them how it compares with their experiences, and finally

(7) Incorporate any changes offered by the participants into the final description of the phenomenon.

\section{Elderly women personal data}

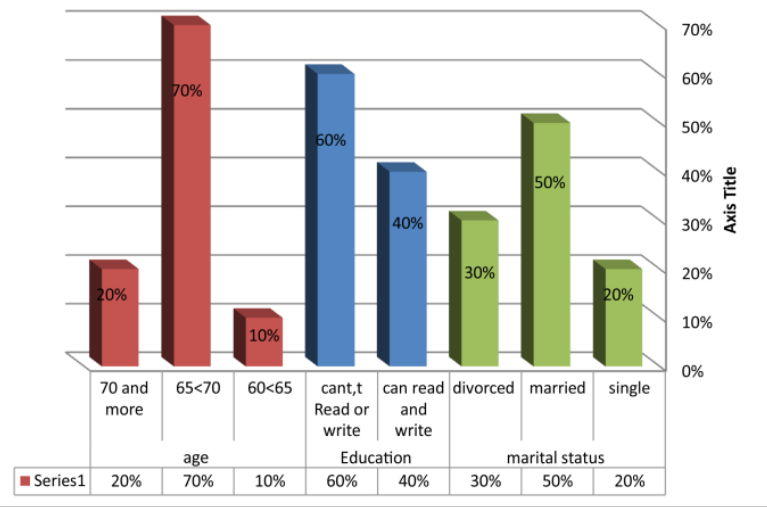

Figure (1) elderly personal data $(n=30)$.

Table 1. Describing themes and subthemes

\begin{tabular}{|l|l|}
\hline Subtheme (s) & \multicolumn{2}{|c|}{ Theme( s) } \\
\hline $\begin{array}{l}\text { living without basic human } \\
\text { needs(food, water, sleep, } \\
\text { \&shelter), Insecurities }\end{array}$ & $\begin{array}{l}\text { l. lack of basic human } \\
\text { needs }\end{array}$ \\
\hline $\begin{array}{l}\text { Self-neglect, poor hygiene, } \\
\text { bad odor }\end{array}$ & $2 . \quad$ Self-care deficit \\
\hline $\begin{array}{l}\text { Aggressive behavior, } \\
\text { depression and isolation, } \\
\text { vision problem, diabetic foot, } \\
\text { loss of family/lack of social } \\
\text { ties, fear, hopelessness. }\end{array}$ & $\begin{array}{l}\text { 3. Bio- psychosocial health } \\
\text { problems }\end{array}$ \\
\hline $\begin{array}{l}\text { Uncertainity, loss of interest, } \\
\text { suicidal ldeation, bad } \\
\text { feeling, feeling lonely }\end{array}$ & 4. \\
\hline Religious,express feeling & Emotional distress \\
\hline
\end{tabular}

\section{Theme 1- lack of basic human needs:}

Subtheme1.1 living without basic human needs (lack of food, water, sleep,\& shelter): Physiological needs are considered the main physical requirements for human survival, including universal physiological human needs (food, waster, sleep).

Participant 1 and 28"I walk with my shirt (I don't have a mouthful) but my god don't forget anyone even the ant".
Participant 3 and 30 "People who are in the street give me their remaining food".

Participant 22 and 18 "I'm eating the food that exists in the garbage"

Subtheme 1.2 Insecurity: Participant 4 and 7" I feel that I am naked all the time"

Participant 8 and 26 "I afraid from people walking at the street"

Participant 15 and 5 "I afraid to die while I'm alone"

Theme 2. Self-care deficit:

Subtheme 2.1 Self-neglect: No one take care about me and I suffered from poor hygiene, not giving sufficient attention or thought to avoiding harm or error, having no care or concern .

Participant 2 and 25 " I don't care after myself "

Participant 9 and 4" I can't even take a shower"

Participant 6 and 14 " We aren't looking or caring for ourselves"

Participant 26 and 8" We are very very negligent in ourselves and all people are afraid of me and keep their arrogance close to me"

Subtheme 2.2 Poor hygiene: Poor hygiene can be a sign of self-neglect which is the inability or unwillingness to attend to one's personal needs. Poor hygiene often accompanies certain mental or emotional psychotic disorders

Participant 5 and 30 "lam unwilling to take care about myself and my personal hygiene"

Participant 14 and 19" I do not care about my personal cleanliness (my clothes are dirty, my hair is dirty uncut and, and I don't cut my nails)" the world"

Participant 10 and 21" I have no desire for anything in

Participant 19 and $27 " \mathrm{I}$ do not have any reasons that make me take care of myself and my cleanliness"

Subtheme 2.3 Bad odor: Body odor is the perceived unpleasant body smell when bacteria that live on the skin break down sweat in to acids. When a body gives off ascent others may find unpleasant it is known as body odor.

Participant 7 and 9" People always say that I have a very bad odor and insects on my skin and hair"

Participant 20 and 14" People avoid to pass near me or come in contact with me and saw that I am contagious". Theme 3- Bio- psycho- social health problems and lack of health care access:

Subtheme 3.1 Aggressive behavior: Aggressive behavior can cause physical or emotional harm to others. It may range from verbal abuse to physical abuse, it can also involve harming personal property.

Participant 11 and 17" The children in the street hit me and I scared them to let me alone.

Participant 24 and 15 "I was cursing any person in the street because I did not want any one to try to hurt me.

Subtheme 3.2 Depression and isolation: Isolation is the process or fact of isolating or being isolated and avoid social contact, depression is a common and serious medical illness that negatively affect how you feel. Depression causes feelings of sadness and or loss of interest in activities once enjoyed.

Participant 30 and 10 "I feel very very sad for myself and for what is happening to me, I don't have interest to do 
anything and no thing have meaning after being in the street".

Participant 27 and 12 "I don't have desire to speak with any human beings and when anyperson trying to talk to me I don't want to respond to him"

Subtheme 3.3 Vision problems: visual pysyological agerelated changes lead to difficulty reading small print so, an elder needs brighter lighting. Eye conditions that could lead to more serious vision problems also become more common with age.

Participant 17 and 22" street dust and the smoke of cars made my eyes like blinded and made me unable to see in front of me and my eyes always burning me"

Participant 23 and 9" I see fog in front of my eyes, made me see things unclear"

Subtheme 3.4 Diabetic foot: A diabetic foot is a foot that exhibits any pathology that results directly from diabetes mellitus or any long term or chronic complication of diabetes mellitus. Presence of several characteristic diabetic foot pathologies such as infection, diabetic foot ulcer and neuropathic osteoarthropathy is called diabetic foot syndrome.

Participant 29 and 24" My two legs was affected by high uncotrolled diabetes (Sugar ate my legs) and my leg was amputated because i did not take the medication regularly.

Participant 12 and 19" No one bring me the medication and I have no insurance and I don't have money to buy it"

Subtheme 3.5 Loss of family/lack of social tie: Family is the basic unit for society and provide individual with feeling of security and sense of power, loss of family had a very bad consequences on individuals.

Participant 20 and 15" Idon't have any relative, all my family were died and no one to ask about me"

Participant 13 and 2 "I'm alone (I am cut from a tree) ,no sons , no wife ,no sister , no brother"

Participant 28 and 11" All my son's left me alone and the whole life became nothing for me"

Participant 21 and 12" My son was an addict, one day he lost his mind and locked me up (closed the door of my room) and stepped on my neck with his lattice so I left my house and I went away"

Subtheme 3.6 Fear: Fear is a feeling induced by perceived danger or threat that occur in certain types or organism, which causes a change in metabolic and organ functions and ultimately a change in behavior such as feeling, hiding or freezing from perceived traumatic event. Fear in human beings may occur in response to a certain stimulus occurring in the present or in anticipation or expectation of a future threat perceived as a risk to body or life Participant 2" I don't sleep all the night because of fear"

Subtheme 3.7 Hopelessness: Have no expectation of good or success.

Participant 18 and 24"I see all the world as black in every way but I'm trying to be patient and say"allah is gracious"

Participant 25 and 15 "I still want today to be my last day and rest from the fatigue in the world"

Participant 2 and 26 " I hope I live in a place and live comfortably"

\section{Theme 4-Emotional distress}

\subsection{Suicidal ideation- Subtheme}

Participant 16 and 19" Suicidal thoughts or suicidal ideation means thinking about or planning suicide .thought can range from a detailed plan to a fleeting consideration. It does not include the final act of suicide".

"Many times I used to think of killing myself and resting from this life. I actually imagined killing myself, and I was also thinking about the way in which my soul died."

Subtheme 4.2 Feeling lonely :Support system is a network of people who provide an individual with practical or emotional support. Lack of support personal may lead to frustration and lack of motivation and depression.

Participant 1and 22" I don't have anyone to ask about me or to care about me, I don't even have friends, and no one can tell me how are you"

Participant 12 and 6 "I am alone, no sons, nor wife, nor father, nor mother, nor brother, nor sister"

Participant 8 and 27 "People help me. I was come with no blanket. Now I have 5 blankets remained, and the street remained better than any other".

\section{Subtheme 4.3 Bad feeling}

Participant 4 and 30"I feel a unpleasant sense that I am hated by all people and that no one loves me"

Participant 6 and 10 "Many hours I feel that I have done a great sin and our Lord saved it from me in this world"

Participant 22 and 8" I see that there is no good salvation in this world, and the brothers are cut off for some money ".

Subtheme 4.5 Uncertinity: Inability to anticipate future, an elder don't know what will happen or what can happen, not near or immediate future but some future far away.

Participant 2 and 7"I spend my life day by day and I don't know what tomorrow will be"

Participant 16 and 18"Idon't want to die while I'm thrown in the street and no one know anything about me"

Theme 5- Strategies for resolution.

Subtheme 5.1 Religious: Religion is a cultural system of designated behaviors and practices, morals, world views, texts, sanctified, places, prophecies, ethics or organization that relates humanity to supernatural transcendental or spiritual elements.

Participant 3 and 25 "I always have confidence in Allah and always pray for his mercy"

Participant 15 and 17 "Many times I think about how god can create a human being and leave him in such circumstances and be in the street".

Participant 14, 9 and 23 "many times saying to myself why god doesn't create me like other people who have money and family to care about me ".

Participant 7 and 15"I pray to Allah, read Quran, look at the sky, and speak to Allah"

Participant 10 and 12 "I'm Praying and crying"

Participant 18 and 22"We support each other"

Subtheme 5.2-Express feeling: to show, manifest, or reveal: to express one's anger. To set forth the opinions, feelings, etc., of (oneself), as in speaking, writing, or painting: He can express himself eloquently.

Participant 29 and 13"We are crying “

Participant 5 and 11 "Sometimes start to screams to relieve stress" 
Similarities \& Differences

\begin{tabular}{|c|c|c|}
\hline Theme & Shared themes & Different themes \\
\hline 1-Lack of basic human needs & $\begin{array}{l}\text { I spent my life day by day and I don't know } \\
\text { what will be tomorrow" }\end{array}$ & $\begin{array}{l}\text { I walk with my shirt but my god don't forget } \\
\text { any one(even the ant)". }\end{array}$ \\
\hline 2-Self-care deficit & $\begin{array}{l}\text { I don't care of myself } \\
\text { I can't take a shower } \\
\text { I do not any reasons to make me take take } \\
\text { about myself and my cleanliness } \\
\text { People avoid to pass near me or contact } \\
\text { with me and saw me as an infection }\end{array}$ & \\
\hline 3-Biopsychosocial health problems & $\begin{array}{l}\text { The children in the street hit me and I scared } \\
\text { them. } \\
\text { I feel sad about myself from what is } \\
\text { happening to me, I don't have interest in } \\
\text { anything and no thing have any meaning } \\
\text { after remaining in the street } \\
\text { the dust in the street and the smoking from } \\
\text { the cars made my eyes like blinded as I } \\
\text { can't see in front of me and my eyes always } \\
\text { burning me" } \\
\text { I'm alone ,no sons, no wife ,no sister, no } \\
\text { brother } \\
\text { I afraid to die while I'm alone } \\
\text { I don't sleep all the night because of fear } \\
\text { "I want today to be the last day for me to } \\
\text { relax from life stress }\end{array}$ & $\begin{array}{l}\text { I was cursing any person in the street } \\
\text { because I did not any one to do anything } \\
\text { for me. } \\
\text { My two legs was affected by uncotrolled } \\
\text { diabetes and my leg was amputated } \\
\text { because I did not take the medication } \\
\text { regularly. } \\
\text { My son was addict he locked the door of } \\
\text { my room and stepped on my neck with a } \\
\text { lattice so I left my house and I went away }\end{array}$ \\
\hline 4-Emotional distress & $\begin{array}{l}\text { I do not know how much I am asking about } \\
\text { me, and I do not care about my friends } \\
\text { I feel a sense that I am hated by all people } \\
\text { and that no one loves me }\end{array}$ & $\begin{array}{l}\text { People help me. I was come with no } \\
\text { blanket. Now I have } 5 \text { blankets remained, } \\
\text { and the street remained better than any } \\
\text { other }\end{array}$ \\
\hline 5-Strategies for resolution. & $\begin{array}{l}\text { Trust in god and always pray for his mercy } \\
\text { Read Quran, look at the sky, and talk to } \\
\text { Allah } \\
\text { We are crying }\end{array}$ & $\begin{array}{l}\text { I'm saying to myself, so much is for me, } \\
\text { our God, what is created, like the rest of } \\
\text { the people" }\end{array}$ \\
\hline
\end{tabular}

\section{DISCUSSION}

Homelessness is connected with decreased life expectancy and increased morbidity rate from both chronic physical and mental health conditions. Current study findings revealed that all homeless elderly female were newly admitted to the shelter within one month and lived in the street for more than 5 years complains from biopsychosocial health problems. This goes with Grenier et al., 2016 who reported that, longer time periods of homelessness have significant health implications for elderly. Our findings revealed multiple barriers and hinders to health care identified by homelessness elderly in the selected shelter home, such as living without essential resources, physical, psychological and social problems, lack of health care acces, emotional distress, self-care deficit and also describing the commonly used strategies for resolution and adaptation with their problems Leng, 2017.

1. Living without basic human needs: Findings of the current study revealed that homeless elderly reported lack of essential life resources including the basic requirements for life such as food, water, shelter, medications and access to health care services these findings go on the same line with the findings of a study done by Hunter, et al , 2015 in Canada and founded that patients struggling with homelessness most frequently reported poor access to basic life resources and required medication, nonadherence, dislike of side effects, cost-related reasons, lack of access to a physician for refills, and lack of belief in, or dislike of, taking medications.similary, in martin 2008 study revealed that For many homeless elderly, access to the basic means of maintaining health was lacking such as shelter, clothing, healthy food, phones, and transportation. Homeless people have no toilets, showers, washers, refrigerators, stoves, or medicine cabinets. Shinn et al., 2007 reported that, support systems and access to resources are consistently presented as preventative measures among homeless subpopulations. Homless elderly health and well-being are highly susceptible to impairment due to the uncertainty of their living environments (Grenier et al., 2016).

2. Self-care deficit Older adults experiencing homelessness have unique needs compared to younger individuals who are experiencing homelessness (Gonyea et al., 2011).

3. Bio- psycho- social health problems and lack of health care acess: Results of the current study shows that homeless elderly experienced a lot of physical, social and psychological problems (vision problems, diabetic food, depression, isolation, loss of family and fear) as a result to poverty, being in the street ,and lack of access to health care that lead to long term complication of patients chronic diseases. These findings matched with the findings of Schembri, 2019 who showed that homeless elderly experienced lack of food, poverty and poor health care services. The expense associated with in adequate food consumption while living in poverty, at times for some, means necessarily going without food and medication. 
Absence of medication predispose elderly to the consequence of exacerbated health conditions and the need for hospitalization and mental health issues such as depression and isolation. In the same respect martin , 2008 also reported in a study that, participants encountered five significant barriers to receiving health care: social triaging, a nonsystem for health care for the homeless, being labeled and stigmatized, being treated with disrespect, and feeling invisible to health care providers. Current ctudy findings also goes with Butler, Maggie, 2017, who reported limited social ties among homless elderly in their study. Frequently, older adults who are exposed to long periods of homelessness develop medical conditions and high rates of poor health earlier than their counterparts who are not experiencing homelessness, creating comorbidity, which complicates their access to resources and social networks (Gonyea et al., 2010; National Coalition of the Homeless, 2009).

4.Emotional distress:The findings of the current study revealed that homeless elderly in shelter home complained of emotional distress including (loss of interest, suicidal ideation, bad feeling and feeling lonely) all of these lead to a lot of bad consequences on elderly people wellbeing these findings agrees with the findings of a study done by Kelsey, 2020 and founded that homeless complained of emotional problems including boredom that led to a range of feelings and emotions that can drive individuals back into despair and the world of addiction and depression also Marshall et al., 2019 found that homelessness had many consequences on elderly people including loss of meaning in life and lack of interest and interesting activities and can lead to negative outcomes including suicidal ideation.

Current study also revealed that homeless elderly were exposed to aggressive behavior and violence in many forms (physical, psychological, sexual, and financial) as a result of being in the street without shelter these findings congruent with the findings of a study done by Bretherton, 2017 and founded that homeless people complained of violence or the fear of violence from other homeless people and from all normal people and these feelings led them to the avoidance of intimacy with other homeless people as a wall for defending themselves against others and to prevent themselves from harm but others wish to form relationships with others beyond their peer group and this driven by a belief that it could be a potential pathway out of their homelessness, it might help them find new levels of positivity and the opportunity to improve their world by transgressing their homelessness.

5. Strategies for resolution: The results of the current study shows that homeless elderly used a lot of strategies for resolution and for coping and adaptation including religion, morals, prophecies and expression of feelings to express one's anger in speaking, writing, or painting. These findings further elucidate the need to prevent and end homelessness among this population. These findings agree with findings of a study done by Fernandez, 2019 and found that homeless used methods for adaptation in the form of outlook for the future, ambivalence and hope and faith, some respondents were able to view their homelessness as a temporary situation and saw the future in a more positive light These individuals were able to plan, imagine owning a home and reconnecting with family in the future. Others held on to faith and high level of spirituality as their source of optimism and capacity to overcome their current circumstances. This study have many strength such as providing highly relevant insights into different biopsychosocial aspects of homelessness experiences of female elderly. Limitation of the current srudy includes; inability to completely bracket researchers's experience entirely, lack of generalizability due to convenience sampling, and absence of a focus group to corroborate the findings of the in-depth).

\section{Conclusion}

Overall the findings of the current study highlighted that, the majority of elderly women has experienced living without basic human needs during homelessness. Biopsych social health problems sucg as (fear, aggressive behavior, depression and isolation, hopeless, Loss of family role, vision problems, lack of financial support, diabetic foot), and self-care deficit (careless, poor hygiene, bad odor) were represented. Using religious and express feeling strategies wer used for resolution as reported by elderly women. findings of current study showed the necessity of meeting the unique and changing needs of this group such as; basic human needs (food, water \& shelter) physical health xare as well as psychosocial support needs.

\section{RECOMMENDATIONS:}

1- Raise awareness about the nature, and process of elderly homelessness phenomena.

2- Conduct psychosocial interventions studies of homeless elderly.

3- Develop community support systems and services for homeless elderly to meet their health needs, and develop coping strategies to alleviate their suffereing and lessen homelessness negative biopsychosocial health impact and sufferring.

4- Enhance the role of media to support homeless elderly, understanding their feelings, needs and difficulties.

\section{REFERENCES}

1. Ahadmin, 2014, Literature Review: Aging and Homelessness, "Homelessness in late life: growing old on the streets, in shelters and long-term care" (project no 4352012-1197)

2. Boggatz, T., Farid, T., Mohammedin, A., \& Dassen, T. 2009. Attitudes of older Egyptians towards nursing care at home: A qualitative study. Journal of Cross-Cultural Gerontology, 24(1), 33-47.

3. Bretherton, J. 2017. Reconsidering Gender in Homelessness. European Journal of Homelessness. Volume: 11, Issue: 1, p.13-29.

4. Brown, R. T., Thomas, M. L., Cutler, D. F., \& Hinderlie, M. 2013. Meeting the housing and care needs of older homeless adults: a permanent supportive housing program targeting homeless elders. Seniors Housing \& Care Journal, 21(1), 126.

5. Brown, R. T., Goodman, L., Guzman, D., Tieu, L., Ponath, C., \& Kushel, M. B. 2016. Pathways to homelessness among older homeless adults: Results from the HOPE HOME Study. PLoS One, 11(5), e0155065.

6. Butler, Maggie K. J.. 2017.."A phenomenological exploration of the lived experiences and human and social capital among older adults using emergency shelters: implications 
for the counseling profession." PhD (Doctor of Philosophy) thesis, University of lowa.

7. Cheung AM, Hwang SW.2004. Risk of death among homeless women: a cohort study and review of the literature. CMAJ, 170:1243-7. 25. Filtzpatrick IJ, Lagory M, Ritchey F. 2007. Just thinking about it: social capital and suicide ideation among homeless persons. J Health Psychol. 12:750-60.

8. Fotheringham, S., Walsh, C. A., \& Burrowes, A.,2013. 'A place to rest': the role of transitional housing in ending homelessness for women in Calgary, Canada. Gender, Place \& Culture.

9. Fernandez, D. 2019. " Something Better than This": A Phenomenology of Unsheltered Homeless Adults in the Miami-Dade Health District (Doctoral dissertation, Barry University)

10. Gilmer TP, Stefanic A, Ettner SL, Mannig WG, Tsemberis S. 2010. Effect of full-service partnerships on homeless, use and cost of mental health services, and quality of life among adults with serious mental illness. Arch. Gen. Psychiatry, 67:645-52.

11. Gonyea, J. G., Mills-Dick, K., \& Bachman, S .S. 2011. The complexities of elder homelessness, a shifting political landscape and emerging community responses. Journal of Gerontological Social Work, 53(7), 575-590.

12. Grenier, A., Barken, R., Sussman, T., Rothwell, D., Bourgeois-Guerin, V., \& Lavoie, J. P. 2016. A literature review of homelessness and aging: Suggestions for a policy and practice-relevant research agenda. Canadian Journal on Aging, 35(1), 28-41.

13. Fazel S, Geddes JR, Kushel M. 2014. The health of homeless people in high-income countries: descriptive epidemiology, health consequences, and clinical and policy recommendations. Lancet. 384:1529-40.

14. Henderson, L., Mott, S., \& Moore, M. 2013. Literature review: Aging and homelessness conducted as part of the SSHRC project: " Homelessness in late life : growing old on the streets, in shelters and long-term care " ( project no 435Authors: Amanda Grenier, Rachel Barken , Tamara Sussman .

15. Hunter, C. E., Palepu, A., Farrell, S., Gogosis, E., O'Brien, K., \& Hwang, S. W. 2015. Barriers to prescription medication adherence among homeless and vulnerably housed adults in three Canadian cities. Journal of Primary Care \& Community Health, 6, 154-161.

16. Kelsey, S. 2020. A Hermeneutic Phenomenological Study of the Lived Experience of Homeless Men (Doctoral dissertation, The Open University).

17. Leila,R 2019. Fighting homelessness in Egypt: 'We are with you, available at http://english.alahram.org.eg

18. Liu, W., \& Estrada-Hernández, N. 2010. Counseling and advocacy for individuals living in poverty. In M. J. Ratts, R. L. Toporek, \& J. A. Lewis (Eds.), ACA advocacy competencies: A social justice framework for counselors (pp. 43-53). Alexandria, VA: American Counseling Association.

19. Leng, G. 2017. The impact of homelessness on health: A guide for local authorities. Local Government Association.

20. Lincoln, Y. S., and Guba, E. G. (1985). Naturalistic inquiry. Newbury Park, CA: Sage.

21. Mabhala, M. A., Yohannes, A., \& Griffith, M. 2017. Social conditions of becoming homelessness: qualitative analysis of life stories of homeless peoples. International Journal for Equity in Health, 16(1), 150.

22. Manal, F. M., \& Magda, A. M. 2018. Causes and Consequences of Street Life on Homeless Children: Choice or Compulsion?. The Medical Journal of Cairo University, 86(June), 1345-1355.

23. Mabhala, M. A., Yohannes, A., \& Griffith, M. 2017. Social conditions of becoming homelessness: qualitative analysis of life stories of homeless peoples. International Journal for Equity in Health, 16(1), 150.

24. Martine, D, 2008. Experiences of Homeless People in the Health Care Delivery System: A Descriptive Phenomenological Study, Public Health Nursing 25(5):42030.

25. Oliveira LP, Pereira ML, Azevedo A, Lunet N. 2012.Risk factors for cardiovascular disease among the homeless and in the general population of the city of Porto, Portugal. Cad Saude Publica. 28:1517-29.

26. Peters, K., \& Halcomb, E. 2015. Interviews in qualitative research. Nurse Researcher, Vol. 22, pp. 6-7.

27. Polit, D. F., Beck, C. T. (2017). Nursing research: Generating and assessing evidence for nursing practice (10th ed.). Wolters Kluwer Health.

28. Seattle, P. H., \& County, K. 2015. Recommended Shelter Health and Safety Best Practice Guidelines. (July).

29. Schröder-Butterfill, E., \& Marianti, R. 2006. A framework for understanding old-age vulnerabilities. Ageing \& Society, 26(1), 9-35.

30. Shinn, M., Gottlieb, J., Wett, J. L., Bahl, A., Cohen, A., \& Ellis, D. B. 2007. Predictors of homelessness among older adults in New York City: Disability, economic, human and social capital and stressful events. Journal of Health Psychology, 12(5), 696-708.

31. Sullivan G, Burnam A, Koegel P, Hollenberg J. 2000. Quality of life of homeless persons with mental illness: results from the course-of-homelessness study. Psychiatr Serv. 1135-41

32. Tsai, J., \& Rosenheck, R. A. 2015. Risk Factors for Homelessness Among US Veterans. 37(23), 177-195.

33. United Nations, P. D. D. of E. and S. A. 2017. World Aging Population 2017. In United Nations New York.

34. Van der Plas AGM, Hoek HW, van Hoeken D, Valencia E, van Hemert AM. 2012. Perceptions of quality of life and disability in homeless persons with schizophrenia and persons with schizophrenia living in non-institutional housing. Int J Soc Psychiatry, 58:629-34.

35. Veer, A. J. E. De, Stringer, B., Meijel, B. Van, Verkaik, R., \& Francke, A. L. 2018. Access to palliative care for homeless people: complex lives, complex care. 1-11. 